\title{
OS DISCOS ERAM COMO OS LIVROS: DISCURSOS FONOGRÁFICOS E A CONSTRUÇÃO DE UMA FONOGRAFIA INSTITUCIONAL NO BRASIL DOS ANOS 1930
}

\author{
RECORDS WERE LIKE BOOKS: PHONOGRAPHIC DISCOURSES \\ AND THE CONSTRUCTION OF AN INSTITUTIONAL \\ PHONOGRAPHY IN BRAZIL IN THE 1930S
}

Denise da Silva de Oliveira ${ }^{1}$

\begin{abstract}
RESUMO: Esse artigo tem como objetivo compreender os discos fonográficos a partir do rastreamento de grupos que buscavam traçar uma fronteira de legitimação em torno da fonografia no Brasil do início dos anos 1930. Para isso, procuraremos enfatizar o caráter histórico desse artefato tecnológico destacando os esforços ligados à construção de seu reconhecimento social e sua recepção entre músicos institucionalizados, intelectuais e outros entusiastas de seu uso "sério", oficial, baseado em um investimento público. Em geral, tratava-se de agentes culturais que tradicionalmente detinham o monopólio da divulgação e preservação de vozes e sons e passaram a ver sua exclusividade esvanecer em função das novas possibilidades franqueadas pela nova mídia. O empenho deles, assim, se associava à tentativa de se inserirem em um renovado mundo fonográfico, alicerçando-o firmemente na ciência e na cultura escrita.
\end{abstract}

PALAVRAS-CHAVE: Fonografia. Disco fonográfico. Tecnologia. Discoteca pública. Música

ABSTRACT: This article aims to understand phonograph records by tracking groups that sought to draw a border of legitimacy around phonography in Brazil in the early 1930s. To do this, we will seek to emphasize the historical character of this technological artifact, highlighting the efforts linked to the construction of its social recognition and its reception among institutionalized musicians,

\footnotetext{
* O artigo refere-se à parte dos resultados obtidos na pesquisa que originou a dissertação "Já escolheu seu disco?': fonografia, ouvintes e a Discoteca Pública do Distrito Federal" (defendida no Programa de Pós-Graduação em História Social da Universidade Federal do Rio de Janeiro em 2020), financiada pelo Conselho Nacional de Desenvolvimento Científico e Tecnológico (CNPq) no período 2018-2020.

1 Mestre em História Social pela Universidade Federal do Rio de Janeiro. E-mail: denise.deoliveira.historia@gmail.com. ORCID: https://orcid.org/0000-0002-9871-8541.
} 
intellectuals, and other enthusiasts of its "serious", official use, based on a public investment. In general, these actors were cultural agents who traditionally had a monopoly on the dissemination and preservation of voices and sounds and started to see their exclusivity disappear due to the new possibilities opened up by the new media. Therefore, their effort was associated with the attempt to insert themselves in a renewed phonographic world, grounding it firmly in science and written culture.

KEYWORDS: Phonography. Phonograph record. Technology. Public record library. Music

“Os discos, hoje, são como os livros. E não nos admiraremos de ver
amanhã 'discotecas' ao lado de bibliotecas" (GRAMOFOMANIA,
$1931: 7)$.

Os ouvintes de música fonográfica (ou qualquer outro material sonoro reproduzido) do século XXI não conseguem conceber uma vida sem a reprodução exata do som; mais que isso, nem sequer param para refletir sobre sua condição de "ouvintes de música fonográfica" dada a invisibilidade de uma prática atualmente tão banal. Por isso, ao nos debruçarmos sobre a trajetória da fonografia brasileira, intuitivamente, não conseguimos depreender que o disco fonográfico pode ter uma história, compreendendo que esse objeto mudou de forma ao longo do tempo (mesmo que amiúde pareça o mesmo) e determinados grupos humanos o absorveram e o empregaram de maneiras distintas, com gestos, propósitos e em espaços peculiares (CERTEAU, 2014).

Assim, a atenção tende a se voltar para uma indústria fonográfica que aparentemente passou a existir somente a partir da década de $1960^{2}$ - mas cujas características são remetidas para toda a primeira metade do século passado ${ }^{3}-\mathrm{e}$ para o disco compreendido apenas como suporte de uma "música popular brasileira" que, quase essencialmente, é base de uma identidade nacional coesa

\footnotetext{
${ }^{2}$ Seguindo Renato Ortiz (1999), que defendeu que a "cultura de mercado" se estabeleceu no Brasil apenas nos anos 1960, Dias (2000), Morelli (2009) e Vicente (2014), em seus trabalhos que dissertam sobre a fonografia brasileira, não coincidentemente evitam o período obscuro que antecede essa década, alegadamente devido à falta ou atomização das fontes ou mesmo em função dessa suposta inexistência de uma indústria cultural no país.

${ }^{3}$ Marcos Napolitano (2007) argumenta, em seu livro A síncope das ideias, que na década de 1960 forjou-se uma tradição que passou a remeter as origens de uma música popular brasileira aos anos 30. Nesse sentido, acreditamos que essa "tradição" possivelmente criada nesse período acabou balizando toda uma historiografia sobre a fonografia brasileira, cujo foco tende a se concentrar na busca por essas "raízes" ou seus desdobramentos.
} 
e tem como finalidade o entretenimento do povo que representa (TINHORÃO, 2014; FRANCESCHI, 2002) - isto quando esse trivial objeto não é simplesmente ignorado e apenas seu conteúdo é evidenciado nas narrativas historiográficas, flutuando sobre o espaço social independentemente de uma materialidade (CHARTIER, 1988).

Se algumas dessas assertivas podem fazer sentido em determinado momento histórico posterior, ou mesmo quando se trata de alguns grupos que angariariam maior simpatia institucional com o passar do tempo ${ }^{4}$, no período que iremos abordar nesse artigo, e no seio da coletividade que enfatizaremos aqui - que não apenas ganhará voz, mas também construirá o seu próprio contexto a partir de suas argumentações e práticas $^{5}$-, nenhuma dessas construções que nos são bastante familiares hoje parecia ter fundamento ou reconhecimento. Isso porque, para músicos formados nos principais conservatórios da antiga capital brasileira, intelectuais e entusiastas de uma fonografia legítima no início dos anos 1930, o disco somente seria respeitado e útil na medida em que estivesse firmemente alicerçado em uma mídia tradicional e em formas sociais de expressão e de validação reconhecidas institucionalmente; em outros termos, no livro, na cultura escrita e na ciência.

\section{Conquistando o reconhecimento: entre a ciência e a verdadeira música}

\footnotetext{
${ }^{4}$ De acordo com Moraes e Machado (2014: 597-598), a partir dos anos 1960, começou a se formar um "amplo espaço de aceitação cultural e social" ao redor das origens, características e agentes associados à música popular urbana, especialmente em espaços culturais institucionalizados, onde antes predominava um interesse pela música de natureza folclórica.

${ }^{5}$ Nesse sentido, é necessário deixar claro que nosso método de trabalho com as fontes se baseia em críticas relacionadas a um "sociologismo" durkheimiano e ao estruturalismo francês cujos resquícios ainda se fazem presentes nos trabalhos historiográficos. O primeiro está ligado à necessidade de explicitação, por parte do estudioso, de um contexto teórico onde os atores são diretamente inseridos, explicando-se o social pelo social (LATOUR, 2012). Nessa perspectiva, a fonografia brasileira dos anos 1930, por exemplo, é encaixada em um contexto dado a priori (Revolução de 1930, Estado Novo etc.) e o que foge dessa circunscrição é ignorado ou artificialmente incorporado para explicar, ratificando, o que já está pronto. Em segundo lugar, também nos afastamos do criticismo estruturalista: não buscamos algo que está "por trás" do que os atores dizem, revelando "verdades ocultas" (DOSSE, 2018a; 2018b); levamos em conta, ao contrário, o que eles falam e como atuam. Desse modo, aqui, tanto o contexto é criado por uma rede de atores - por meio do que falavam/escreviam e faziam - quanto o "social" está por ser construído.
} 
No início do século XX, Olavo Bilac demonstraria todo o seu desprezo pela fonografia em uma crônica publicada na revista Kosmos. Segundo o poeta, a famosa rua do Ouvidor, no Rio de Janeiro (então capital da República), havia se transformado em uma "galeria do Inferno" graças às máquinas falantes ou cantantes que despejavam vozes esganiçadas por toda a via pública: "eram urros, gemidos, garganteios, frenéticos, imprecações, ganidos, cacarejos, miados, latidos, mugidos, arrulhos, guinchos, berros, grunhidos" (BILAC, 1907: 3). Os sons fonográficos, de fato, podiam ser vistos (ou escutados) como uma cópia malfeita de um som verdadeiro, original, como revela um suposto diálogo entre dois amigos publicado na revista Fon Fon em 1916:

O meu amigo Pires que detesta tais máquinas e outro dia, falando delas, dizia-me assim:

- Não gosto de conservas.

- Conservas?!

- Sim, homem de Deus, se ei de comer peixe de lata, compro um robalo fresco; se ei de beber vinhos saturados de álcool para se conservarem, prefiro chopes; se ei de ouvir música de conserva nos zonofones malditos, ouço piano ou violino (JOTAENNE, 1916: 39).

Enquanto isso, nas alíquotas de tributação do governo brasileiro, discos, cilindros (que os antecederam) e os dispositivos que os reproduziam eram classificados, nessa mesma época, como "artigos de fantasia", o que enfatiza o caráter mágico que ainda orbitava em torno dessas duvidosas máquinas (FRANCESCHI, 2001: 31-32).

Essa impressão um tanto ou quanto negativa com relação à tecnologia fonográfica seria novamente destacada algum tempo depois com um novo propósito: demonstrar que essa fase "imperfeita" da fonografia, fundamentada em energia mecânica, havia passado e naquele momento o mundo começava a desfrutar de uma etapa em que essa técnica moderna fora aperfeiçoada sobremaneira. Estamos nos referindo a meados da década de 1920. Nesse período, um fonógrafo renovado apareceria, dessa vez baseado em um sistema elétrico de funcionamento - modelo criado nos Estados Unidos em 1924 para concorrer com o rádio, que começava, de forma profícua, a se desenvolver naquele país e a rivalizar com a fonografia (MORTON JR., 2006: 64-66). No 
Brasil, essa grande mudança de paradigma viria acompanhada da estreia, em 1926, da primeira coluna da imprensa periódica dedicada aos assuntos relativos às chapas fonográficas e seus dispositivos de reprodução: "Discos e máquinas falantes", do jornal carioca $O$ Paiz.

Esse espaço destinado aos assuntos atinentes aos discos e seus aparelhos de reprodução teria como objetivo realizar um "esforço em prol do desenvolvimento e da propaganda do fonógrafo em nosso país" (O Paiz, 19 jun. 1927: 12), funcionando também como uma "literatura de aconselhamento", com todo um "corpo de instruções", para os leitores que buscavam se aperfeiçoar e compreender as novidades que apareciam em profusão naquele momento, participando eles mesmos ativamente desse movimento de divulgação - perfil parecido com o de outros veículos da imprensa periódica que se imbuíam dessas mesmas finalidades na época (VELLOSO, 2010: 50; 8687). Nesse sentido, a atuação daqueles novos ouvintes de fonógrafos, ávidos por aprender e consumir, se torna um dos pontos mais interessantes que permeiam essa fonte histórica.

Os ouvintes de sons fonográficos, os "fonófilos" ou "discófilos", recorriam à coluna semanal d'O Paiz, por meio de correspondências enviadas à sede do jornal, para o saneamento das mais variadas dúvidas com relação ao consumo de discos e à utilização de seus aparelhos. Nessa perspectiva, os especialistas em fonografia que respondiam as cartas e produziam os artigos da seção não se furtavam de direcionar a compreensão dos leitores-ouvintes no que concernia aos mais diversos assuntos. Precipuamente, as explicações acerca do funcionamento dos fonógrafos apareciam repletas de detalhes técnicos, inclusive acompanhados de alguns princípios básicos da física, que serviam não apenas para forjar um melhor entendimento no que tange à propagação do som, mas também como um meio de reforçar o papel da ciência no aperfeiçoamento paulatino daquela maravilha gerada pela modernidade. Segundo argumentavase, essa ênfase não era fortuita, tampouco impositiva: os fonófilos, "em sua maioria, preocupam-se extraordinariamente com a parte científica de qualquer máquina falante" (O Paiz, 11 mar. 1928: 13). 
Assim, se houve um tempo em que "gente séria e competente" declarava que a fonografia teria um "futuro restrito", pois não passava de um brinquedo “cuja voga seria evidentemente passageira", esse estágio havia passado (O Paiz, 8 jul. 1928: 16). Sob a égide da ciência, de seu contínuo avanço, as expectativas quanto ao destino dos discos e dos fonógrafos não poderiam ser maiores, tendo em vista que o principal objetivo das inúmeras pesquisas e inventos empreendidos na área fora alegadamente alcançado, a saber, "a reprodução fiel e rigorosamente exata do timbre, da tonalidade e das diferentes modulações dos sons, tanto para a voz como para a música" (O Paiz, 12 jun. 1927: 12) ${ }^{6}$.

A chancela científica - e sua consequência mais imediata: o aparecimento de um fonógrafo mais perfeito auditivamente - se consubstanciaria em um passo importante para a legitimação do disco junto à "gente séria e competente", mas era insuficiente para esse artefato deixar de ser visto como um "artigo de bazar" (O Paiz, 8 jul. 1928, p. 16) e alçar voos mais altos dentro de um campo social "respeitável". Dessa maneira, se escutar um som como "se o artista estivesse presente" era uma necessidade premente, conseguir comparar um álbum de disco a uma "luxuosa edição de livros" era um esforço comum empreendido pelas fábricas, que tiveram uma grande preocupação de ligar seu produto - que ainda poderia ser alvo de muitas desconfianças - a um corpus de elementos socialmente conhecidos e reconhecidos; como podemos ver na figura a seguir, uma peça de propaganda da empresa americana Victor divulgada pela casa de discos brasileira Paul J.

\footnotetext{
${ }^{6}$ Atentar para o discurso da fidelidade sonora não significa, sob o ponto de vista do pesquisador, comparar as diferentes tecnologias de reprodução sonora e seu suposto avanço ao longo de tempo - enfatizando que em um momento o som fonográfico soava mal, depois passou a soar melhor, em seguida chegou à perfeição etc. Deixemos essas defesas para os atores, cujas argumentações devem nortear-nos quanto à importância dessa propalada fidedignidade em determinado momento histórico. Afinal, como Jonathan Sterne (2003: 274) destacou, a "fidelidade sonora era, então, mais sobre encenar, solidificar e apagar as relações de reprodução de som do que refletir sobre qualquer característica particular do som reproduzido. Se perfeita fidelidade simplesmente significava um conjunto de relações sociais e sônicas no qual os participantes poderiam ter fé, não é de se surpreender que encontremos declarações repetidas sobre reprodução perfeita dos anos 1870 até hoje" \"Sound fidelity was, thus, more about enacting, solidifying, and erasing the relations of sound reproduction than about reflecting on any particular characteristics of a reproduced sound. If perfect fidelity simply meant a set of social and sonic relations in which participants could have faith, it would be no wonder that we find repeated declarations of perfect reproduction from the 1870s on down to the present".
} 
Christoph \& C., esses ingredientes iam de obras clássicas de literatura, que formariam uma bela biblioteca, a orquestras de música, que se remetiam a um tradicional concerto musical.

Figura 1 - Propaganda da empresa Victor divulgada pela Paul J. Christoph \& C.

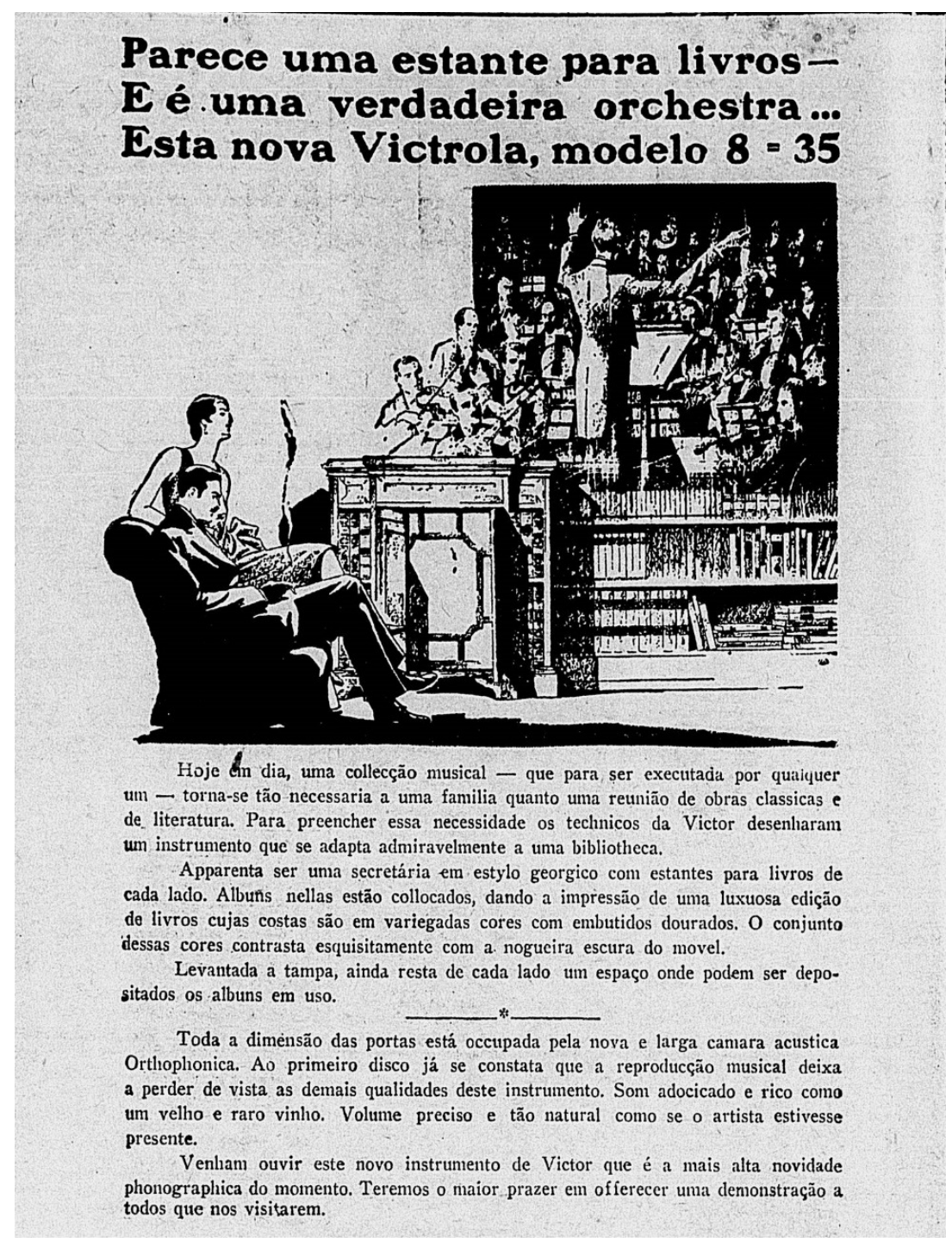

Fonte: Biblioteca Nacional, O Paiz, 24 jun. 1928: 12.

Nesse período, “álbum” tinha um significado estritamente físico: era um livro grande em que se dispunham os vários discos que compunham um fonograma e podiam ser folheados quando ali arranjados (MORTON JR., 2006: 
92). Sua importância nessa época é bastante significativa haja vista que o seu uso era o único meio de se disponibilizarem, para os consumidores, chapas fonográficas contendo música erudita - outra ponta de legitimação da qual se lançaria mão nesse momento. Isso porque os discos desse período, de 78 rotações por minuto e feitos de goma-laca, só permitiam que fossem gravados até quatro minutos de material sonoro em cada face, o que excluía incontáveis expressões musicais que antecederam a tecnologia fonográfica, em especial as grandes peças - sonatas, óperas, concertos etc. - da chamada música verdadeira ou imortal in $^{7}$.

A ligação da música erudita ocidental, ou "música clássica", a uma verdade ou imortalidade estava associada ao fato de essa expressão musical se vincular à então única forma sonoro-artística institucionalizada, fundamentada em proposições científicas, ademais de tradicionalmente ter uma certa exclusividade no que concernia à possibilidade de conservação além do espaçotempo em que fora elaborada e executada. Antes dos discos, uma sonoridade somente poderia ser preservada - e divulgada mais amplamente - por meio da escrita, das partituras, que são formadas por símbolos escriturários cuja compreensão está subordinada a uma decodificação dominada apenas por alfabetizados musicalmente, por técnicos (ONG, 1998: 98). Em outras palavras, a retenção e a preservação do som estavam condicionadas ao uso de uma linguagem escrita (KITTLER, 2017: 97) que delimitava e normatizava as sonoridades, excluindo os tipos sonoros que não se enquadravam na afinação da escala temperada ocidental e em uma divisão rítmica bem delimitada (WISNIK, 1989).

E era a esse elemento conhecido e reconhecido, para além da recentíssima cultura fonográfica, que o disco fonográfico deveria ser, também, associado se a intenção era revesti-lo de uma veracidade e uma respeitabilidade das quais ele ainda carecia. Não à toa, na coluna "Discos e máquinas falantes",

\footnotetext{
${ }^{7}$ A música erudita ocidental era assim chamada na imprensa, na própria coluna "Discos e máquinas falantes", e por músicos institucionalizados que, certamente, pretendiam diferenciá-la das músicas fonográficas que eram criadas sem um rigor científico e fora da chancela dos conservatórios e escolas de música.
} 
espalhavam-se semanalmente "dicas" pelo espaço que a perfazia tais como: "Aprenda a gostar de boa música, principalmente de música clássica, por meio dos discos. Ouvir em casa, com atenção um trecho de boa música, representa mais que muito concerto" (O Paiz, 12 dez. 1926: 14, grifos nossos). O "trecho", mais uma vez, dizia respeito às limitações da fonografia do período: como os discos só comportavam quatro minutos de material sonoro em cada lado, frequentemente, as fábricas optavam por resumir a peça musical que originalmente abrangia vários minutos de execução, quando não utilizavam a dispendiosa alternativa de a gravar completa em diversos discos que eram acomodados em álbuns.

Por sua vez, aquela restrita comunidade de ouvintes não se eximia de pontuar que sua preferência se direcionava para a música erudita: de um leitor identificado como Raul Smith - que preferia "sempre comprar as chapas de música clássica" (O Paiz, 26 jun. 1927: 14) - ao médico "Dr. Aristides" - que tinha uma predileção que se acentuava "para a música clássica tocada por orquestra" (O Paiz, 15 maio 1927: 13). Da mesma forma, outros discófilos eram incentivados, ao procurarem se informar sobre como deveriam agir diante de seu aparelho, a utilizar seu fonógrafo para emular em sua casa, em reuniões privadas, espaços célebres da cidade que patrocinavam a escuta de música erudita do modo tradicional (que chamaríamos hoje de "ao vivo"), como o Teatro Municipal: "Outra condição essencial é que tente imitar com sua máquina uma verdadeira orquestra" (O Paiz, 22 maio 1927: 14, grifos nossos). Afinal, por meio da nova fonografia - que havia deixado os antigos fonógrafos mecânicos, meros "brinquedos", para trás - era possível escutar em qualquer lugar, e de forma fidedigna, a verdadeira música.

\section{Da cultura escrita ao disco fonográfico (e vice-versa)}

Fábricas de discos e máquinas falantes e seus colaboradores da imprensa não tinham mais dúvidas quanto ao novo lugar que a fonografia poderia ocupar na reorganização sociocultural do Brasil. Essa tecnologia, fruto do avanço progressivo da humanidade, poderia colaborar tanto para a divulgação da 
música clássica - cujos artistas deixariam sua arte registrada no fonógrafo também para a posteridade - quanto para a preservação do "folclore musical de nossa terra”, que, se antes tinha uma conservação restrita fiando-se apenas nos recursos da escrita, a partir daquele momento poderia ser "transplantado" para a máquina falante "em todos os seus detalhes" em função da qualidade dos novos discos elétricos (O Paiz, 24 jul. 1927: 8).

Mas se, por um lado, esse empenho de forjar um maior reconhecimento para as chapas fonográficas caminhava a passos largos entre empresas do ramo e especialistas entusiastas que eram incumbidos de fazer sua propaganda, por outro, ainda poderia haver setores especializados, que tinham tradicionalmente um papel de destaque no que concernia à reprodução e preservação sonora, que duvidavam de seus papeis social e cultural. Esse foi o caso do professor Custódio Fernandes Góes, que escreveu uma carta pública se queixando do mau uso da técnica fonográfica - além de suas limitações; um "brado de protesto" que seria divulgado na seção "Correio Musical" do jornal fluminense Correio da Manhã.

Apresentando-se como "brasileiro", "artista músico" e "professor livre docente da cadeira de piano no Instituto Nacional de Música, onde trabalho desde 1904", Fernandes Góes afirmaria em seu texto que escutara alguns discos, de fábricas nacionais e estrangeiras, com gravações do hino nacional "onde o original de Francisco Manoel da Silva é estupidamente adulterado, com uma execução absurda", o que constituía um "atentado, uma injúria assacada à composição, um ultraje à memória do compositor", que teve sua "verdadeira inspiração" rebaixada, precisando-se assim de uma "pronta e enérgica correção" (GÓES, 1930: 7). Outra reclamação se conectava às deficiências técnicas identificadas nessa nova mídia: "Envio ainda outro disco [...] mutilado completamente em sua admirável entrada, com a ausência total daqueles quinze compassos da introdução, que prepara, eletriza o ambiente, num incontido arroubo de entusiasmo" (GÓES, 1930: 7). Essa "mutilação" estava associada, claramente, aos limitantes quatro minutos que então prendiam todos a uma "escuta atomizada" - como classificaria negativamente o filósofo Theodor 
Adorno (2002: 305) -, que ia de encontro a toda uma tradição musical que desconhecia uma demarcação temporal tão restritiva (KATZ, 2010: 36).

E seria a um dos alicerces dessa tradição que o professor Custódio recorreria para apresentar o modelo ideal de execução da sonoridade máxima da nação. Juntamente com alguns discos, Fernandes Góes enviaria para a seção do periódico um "clichê" da partitura original da composição de Manoel da Silva seguido de uma sucinta análise, por meio dos quais o leitor poderia compreender por que o reclamante estaria correto em suas assertivas: veja os “compassos $33^{\circ}$ e $34^{\circ}$ "; essa "ligação melódica"; aquela "sucessão de acordes"; esta "entrada da "reprise em oitavas"; sem contar a omissão de um "belo arpejo, com suas tão características appoggiaturas sobre as quiálteras" (GÓES, 1930: 7). Em suma, um exame técnico que poderia ser realizado, e compreendido, somente pelos poucos que dominavam a linguagem escrita musical - antigo meio exclusivo de reprodução e preservação sonora.

Apesar desse pessimismo que se associava a uma comparação com antigas, e mais reconhecidas, mídias de armazenamento de informação sonora, um movimento nos círculos artístico e musical começava a se sobressair em meio a uma ou outra oposição: a defesa do disco como um suporte de material sonoro fidedigno. Estava incluída nesse empenho a coluna de Augusto Lopes Gonçalves "Discando", publicada semanalmente na seção do Correio da Manhã dedicada aos assuntos fonográficos, denominada "Música em discos". O "professor doutor Augusto", como era chamado, era um ativo crítico musical e artístico da capital federal que então ocupava o cargo de secretário geral da Associação dos Artistas Brasileiros (Diário de Notícias, 29 out. 1931: 5), tendo participado da Comissão de Música encarregada de elaborar o plano de reestruturação do ensino musical superior que integrou o Instituto Nacional de Música, ao qual nos remeteremos mais detidamente adiante, à Universidade do Rio de Janeiro, em companhia dos professores daquela instituição Francisco Braga e Oscar Lorenzo Fernandez - com quem ele também editava uma revista, a Ilustração Musical (Correio da Manhã, 4 jul. 1930: 8; 12 abril 1931: 4). 
A coluna "Discando" estreou em 1930 e até 1933 era publicada sem assinatura. Mas apesar de aparentemente constrangido de defender o disco fonográfico diante do ceticismo que o circundava, Augusto Gonçalves tecia diversas críticas a uma minoria que insistia em se manter na "idade da pedra" ao ignorar os benefícios que as novas máquinas falantes elétricas poderiam levar para os ambientes artístico, político e historiográfico do Brasil (Correio da Manhã, 4 maio 1930: 7). Isso porque, além da música, a realidade nacional poderia, de diversas formas, ser transposta para os sulcos que se desenhavam sobre as chapas negras com fins de documentação e preservação, especialmente naquele momento em que se celebrava a "absoluta imparcialidade" que revestiria a nova fonografia. Para o secretário geral da Associação dos Artistas Brasileiros, deveria haver, por exemplo, microfones no Congresso Nacional para, ao gravarem-se as sessões "com pasmosa fidelidade", nenhuma palavra proferida ficar perdida e as orações parlamentares poderem ser "apreciadas tal e qual foram pronunciadas, com as inflexões próprias do orador e a maneira pessoal que este tiver de encarar a eloquência e a gramática" (Correio da Manhã, 8 jun. 1930: 7, grifos nossos). O ideal, na visão do colunista, era que se construísse uma "Discoteca Parlamentar Nacional", percepção que se mostraria oportuna em 1933, no contexto da Assembleia Nacional Constituinte, quando Lopes Gonçalves destacaria crenças basilares que cercavam então o disco e a reprodução sonora: fidedigno, incorruptível, eterno e historiográfico, essa maravilha moderna possibilitaria, acima de tudo, o alcance dos ouvidos das gerações futuras.

Estamos num dos momentos mais propícios para o emprego do disco como documento notável para o estudo da história.

$[\ldots]$

Ora o discurso impresso não é a mesma coisa que o discurso pronunciado (não é por muitas razões) e assim nada igualaria a sua conservação em disco, que guardaria para a eternidade a voz e a eloquência do orador.

[...]

Amanhã, com toda a facilidade, seriam reconstituídas as eruditas discussões travadas em torno da nova Constituição e nas comemorações da data da nova Carta poder-se-ia reproduzir algumas das mais interessantes sessões em que ela foi votada. 
Com isso, os que então tinham feito parte da Assembleia se sentiriam obrigados a continuar com um pouco mais de respeito pelo que haviam dito e os pósteros se edificariam com as lições dos licurgos cimentadores da República Nova.

De mais o disco conservaria com toda a fidelidade o discurso, com as inflexões da voz do orador e a sinceridade da construção das frases, visto que se tornaria impossível essa colaboração posterior que a revisão costuma trazer (Correio da Manhã, 19 nov. 1933: 11, grifos nossos).

Assim, o disco se mostrava uma mídia particularmente singular ao possibilitar a gravação de sons e vozes reais, com uma absoluta fidedignidade. Mas ao mesmo tempo, esse artefato deveria estar alicerçado sobre bases sólidas em termos de conteúdo, principalmente quando se pensava na escuta infantil em paralelo com a "finalidade maravilhosamente civilizadora da fonografia". Isso visto que às crianças deveriam ser proporcionadas audições de "pessoas notáveis em pequenas e úteis alocuções", do hino nacional (gravado de forma correta, obviamente) e de músicas escolares, em especial aquelas relativas aos cantos corais (Correio da Manhã, 21 set. 1930: 11). Anseio que poderia ir ao encontro das perspectivas daquele novo momento histórico que se vivia, quando, pela primeira vez, o país iria dispor de um ministério exclusivamente voltado para a educação, proposta do novo governo instituído após a tomada do poder por militares e civis ligados ao político gaúcho Getúlio Vargas. Nesse sentido, de acordo com Augusto Gonçalves, a técnica fonográfica teria

de figurar no primeiro plano das cogitações do futuro ministro, como veículo maravilhoso da cultura musical. Prestando atenção, auxiliando a esta modalidade artística, o governo irá preparando um dos meios mais eficazes para o apuramento da mentalidade geral. Acelerará o crescimento de importantíssima indústria nacional, igualmente, e tornará realidade o aproveitamento completo de todas as vantagens que a fonografia é capaz de proporcionar. É que o disco, como aqui tantas vezes temos escrito, além de deleitar, instrui, e não só pela música como auxiliando de mil modos o estudo das ciências e das línguas nas escolas.

São sem conta as utilidades da fonografia, as quais dia a dia, crescem e mais admiráveis se tornam. A todos os domínios do saber humano ela presta incalculáveis serviços, que por outros meios seriam impraticáveis. Que, pois, ela entre como importante ponto do programa de ação do ministro da instrução e ver-se-á sem tardança do que ela é capaz. E assim teremos realizações de excelso mérito, inclusive a Discoteca 
do Folclore Brasileiro, que será um dos monumentos capitais da nossa música e será obra sem par no resto do mundo (Correio da Manhã, 16 nov. 1930: 4, grifos nossos).

Não obstante, o grande problema identificado estava relacionado à incipiente indústria discográfica brasileira, de base comercial, que estaria se voltando cada vez mais para as músicas ligeiras, que apareciam e sumiam dentro de uma nascente cultura fonográfica progressivamente fugaz - em tudo diferente da música imortal, portanto -, perdendo-se a oportunidade inédita de se utilizar legitimamente um meio que viabilizava a preservação real do som. Nesse sentido, o que mais aborrecia o colunista eram as letras dos "sambas, valsas e cançõezinhas frágeis" - as expressões musicais que estavam sendo engendradas no âmago da fonografia, carregando todas as suas características (inclusive seus limitantes três ou quatro minutos de duração). Para Augusto Lopes Gonçalves, os textos que compunham essas novas músicas fonográficas eram quase sempre "verdadeiros apanhados de disparates, sem pé nem cabeça, acervo de frases sem nexo e do mais penoso mau gosto", atributos que seriam particularidades das produções locais, uma vez que "em toda parte, as letras das músicas populares, conquanto não sejam monumentos literários, são perfeitamente aceitáveis, têm sentido e obedecem à gramática", qualidades que os idealizadores brasileiros não conseguiriam conceber em seus trabalhos por serem analfabetos (Correio da Manhã, 1 jun. 1930: 7, grifo nosso).

Assim, caberia aos alfabetizados, gramaticalmente e musicalmente, a coibição desse mundo oral urbano sem freios - agora divulgado e conservado em uma mídia que dispensava os domínios da escrita, essa forma de expressão social que ordena o material linguístico e sonoro e, como referência institucionalizada para falantes e ouvintes, persegue um controle de mudanças e usos (GOODY, 2000: 143-144). Mais um passo para a legitimação, e posterior institucionalização, da fonografia deveria ser dado, antes que ela retornasse para sua condição de "brinquedo" que renunciava à respeitabilidade. E esse novo movimento deveria ser guiado por uma comissão de pessoas idôneas - ou seja, que estavam sob a égide de uma legitimidade institucional -, que deveriam “cooperar com fábricas no progresso artístico e moral do nosso disco, a fim de 
que este corresponda por completo à sua indiscutível finalidade de grande educador do povo" (Correio da Manhã, 18 jan. 1931: 10).

\section{As vozes do Instituto Nacional de Música}

No início de 1931, um inquérito intitulado "Os discos e os músicos" seria lançado na mesma seção do Correio da Manhã em que Augusto Lopes Gonçalves publicava. O objetivo dessa lista de perguntas, que seria respondida por artistas de "elevado mérito" ao longo de algumas semanas (Correio da Manhã, 11 jan. 1931: 4), era apurar o que "as principais figuras do nosso meio musical" pensavam "a respeito do disco" para, assim, reunirem-se “ensinamentos cuja divulgação trará, de certo, grande proveito ao progresso da fonografia nacional" (Correio da Manhã, 18 jan. 1931: 10). Não coincidentemente, os detentores do direito à voz no que tange a esse tema se encontravam, sobretudo, na principal escola de música da capital brasileira: o Instituto Nacional de Música.

As origens do Instituto podem ser remetidas ao século XIX. Quando as cidades latino-americanas começaram a receber conservatórios e escolas de música, no final do oitocentos (GONZÁLEZ, 2015: 92), o Brasil já possuía a sua própria instituição voltada para o aprendizado musical. Conquanto procedesse da época do Império - como o Conservatório de Música imperial, depois transformado em uma seção da Academia de Belas-Artes -, foi na República que o Instituto Nacional de Música, sua nova denominação, viu sua importância social crescer. Entre 1890 e a década de 1920, conforme Avelino Romero Pereira, estruturou-se em sua órbita uma nova elite musical - composta de nomes como Leopoldo Miguéz, Alberto Nepomuceno, Francisco Braga e Alfredo Bevilacqua - que buscou atuar de forma bastante incisiva na arena pública, com o fito de participar da construção de uma identidade nacional republicana (PEREIRA, 2007).

No início da década de 1930, com o crescimento da fonografia, essa importante instituição musical e seus músicos se viram diante de um desafio: sua antiga exclusividade com relação aos sons nacionais, que podiam ser mais 
amplamente divulgados e preservados por meio das partituras, fora parcialmente perdida para amadores que se aventuravam em um atualizado mundo musical que surgia no bojo das possibilidades de retenção sonora propiciadas por essa nova mídia, o disco. No que lhes concernia, esses novos atores que se beneficiavam da técnica fonográfica - músicos considerados analfabetos, não-profissionais, que se inventavam por meio da "música de conserva" - por vezes ostentavam sua recente posição de destaque, sua própria condição de novo diante do ultrapassado. Assim acreditava Orestes Barbosa (1933: 181-182), para o qual o "sarcófago da rua do Passeio" (endereço do Instituto) era um entrave para o desenvolvimento da arte, pois os músicos que de lá saíam ficavam "em geral presos à gramática das pautas".

Por outro lado, era no Instituto Nacional de Música que se guardava um trunfo importante: como mencionado, o disco ainda era uma mídia bastante frágil em termos de legitimidade, e, nesse sentido, o papel da música erudita para seu reconhecimento se tornava crucial. Desse modo, se para alguns a "gramática das pautas" era o velho diante do novo, para um mundo, digamos, institucional, os vereditos dos professores que a ensinavam poderiam ser essenciais para o emprego da fonografia em projetos "sérios" - em programas governamentais, por exemplo. Prova disso está no supracitado inquérito divulgado no Correio da Manhã, nas escolhas que foram feitas com relação a quem tinha a legitimidade para falar da fonografia e da música - a verdadeira, não a "de conserva".

Com efeito, o primeiro a ter suas concepções acerca da fonografia divulgadas nesse jornal foi Lorenzo Fernandez, compositor e professor catedrático do Instituto Nacional de Música. Apesar de ainda titubear quanto às características correntes do disco, afirmando que seu potencial de possuir um "alto valor documental" estava comprometido pelas limitações de cunho técnico - ligadas aos cortes na escuta, que acabavam sendo produzidos pela troca de faces e chapas no meio das peças em função da restrição do armazenamento de som, e a um persistente chiado -, Fernandez declararia que o 
disco poderia se tornar um excelente instrumento de preservação e divulgação cultural por meio de um investimento estatal:

Como fator de cultura, o disco será maravilhoso quando não visar a parte mercantil. Creio que isso só poderá ser obtido com a contribuição e o controle do Estado.

As suas possibilidades são estupendas: já pela criação de discotecas de folclore; já com a gravação integral das grandes obras nacionais etc.

Nos países de grande extensão e pouca cultura, como o nosso, no qual o meio, ainda paupérrimo, torna impossível a existência do artista, o disco exerce um papel importantíssimo na obra cultural, apesar dos preços exorbitantes (Correio da Manhã, 18 jan. 1931: 10, grifos nossos).

Já para Francisco Braga, professor catedrático de contraponto e fuga e composição do Instituto, o disco, naquele contexto, seria "depositário fiel do pensamento, que zelosamente guarda; é a memória que não morre; o livro sonoro em cujas páginas toda inspiração se condensa, incrustada na cera mágica de sua composição genial” (Correio da Manhã, 25 jan. 1931: 10, grifos nossos). Ademais, o compositor não se esquivava de analisar os supostos paradoxos que rondavam o disco: "O maravilhoso disco sempre rodando, espalha, difunde pelo mundo inteiro o belo e o horrível, o sensato e o grotesco" (Correio da Manhã, 25 jan. 1931: 10, grifos nossos). Em suma, em seu ponto de vista,

O disco é o professor ideal. Pelo disco, o ensino da música nas escolas primárias torna-se menos árduo; interessa mais à criança que a própria palavra do mestre, monótona por vezes. $\mathrm{O}$ disco traduz fielmente, exatamente, o pensamento que se quer incutir, e a lição, reproduzida muitas vezes vai pouco a pouco conquistando a memória da criança que consegue, finalmente, aprendê-la, sem menor esforço de inteligência, mecanicamente, pela simples sedução do disco (Correio da Manhã, 25 jan. 1931: 10, grifos nossos).

Enquanto isso, na visão de Luciano Gallet - diretor do Instituto Nacional de Música e compositor que vinha se inspirando no folclore brasileiro para produzir seus trabalhos musicais -, a fonografia poderia se transfigurar em um "extraordinário fator de desenvolvimento da cultura musical", pois

o disco, praticamente só ele, excluídos os exemplos que o professor pode apresentar aos alunos, abre e prepara o 
caminho da educação musical. E se for bem aproveitado $\mathrm{em}$ caráter sério, com audições organizadas criteriosamente, dará pleno e belo cumprimento à sua missão. Dará, como auxiliar de professores conferencistas, uma educação musical completa. Assim haverá conhecimento completo da arte. Os clássicos serão apreciados através mesmo das suas grandes obras, e o mesmo se dará com os demais grupos de compositores em que se divide a história da música [...] (Correio da Manhã, 1 fev. 1931: 7, grifos nossos).

Comentando sobre seu trabalho na Academia Brasileira de Música, da qual foi criador e era então presidente, Gallet ainda afirmaria que esta agremiação havia acabado de entregar um memorial ao governo demandando mais atenção ao ensino da música, que deveria se tornar obrigatório nas escolas primárias, e à "educação progressiva pelo disco", com a finalidade de se iniciarem "as crianças nas ideias gerais sobre os grandes períodos da história da música" (Correio da Manhã, 1 fev. 1931: 7). Outra sugestão, que dialogava com sua preocupação acerca do folclore nacional, seria a organização de uma discoteca em benefício da preservação das sonoridades genuinamente brasileiras:

Por meio de uma discoteca realmente folclórica manter-se-á o povo sempre dentro do seu verdadeiro ambiente musical. Assim aquele ficará a coberto do abastardamento do seu gosto gerado pela corrupção que trazem os compositores em busca de inspiração nas músicas estrangeiras e tentando efeitos com o emprego de processos que de modo algum correspondem à psicologia artística de nosso povo.

Registrando as músicas populares na região a que pertencem e por artistas locais, o disco desempenhará o miraculoso papel de salvador do folclore brasileiro (Correio da Manhã, 1 fev. 1931: 7, grifos nossos).

Uma representação jovem da "verdadeira música" que respondeu aos pontos elencados pelo Correio da Manhã foi personificada por Luiz Heitor Corrêa de Azevedo. O músico, que no período se aprofundava em composição com o professor Lorenzo Fernandez, acreditava que "o papel da fonografia na civilização contemporânea tem de ser o de divulgadora das grandes obras" (grifo nosso), porque

É inútil insistir sobre o valor do disco como elemento de divulgação, como pioneiro, ousado batedor da cultura musical. Sem sair do Rio de Janeiro, quantas obras, ouvidas por centenas de amadores fonográficos, seus próximos e convidados, ainda não fizeram aparição em nossos concertos. 
Leio num Catálogo Columbia a gravação de um curso de história da música, por Paul Landormy em 20 discos, com exemplos musicais, dos tempos da antiga Grécia ao drama wagneriano. O que não representa a fonografia assim orientada como agente de ilustração, de preciosos ensinamentos, mormente num centro como o Rio em que a cultura artística conta com tão raras oportunidades favoráveis? (Correio da Manhãa, 22 fev., 1931: 4, grifo nosso).

De modo similar pensava Albuquerque da Costa, o último professor do Instituto Nacional de Música entrevistado. O "pedagogo esclarecido", como seria chamado no texto, pontuaria que se "até há algum tempo" tinha-se "verdadeiro horror pelo disco", considerado "uma caricatura de mau gosto da música", naquele momento, vivia-se um clima de curiosidade com relação à técnica fonográfica, incluindo ele próprio, que fora um dos "horrorizados":

Hoje sou forte entusiasta da fonografia, cujos progressos cada vez mais admiro. Já agora é o caso de se não mais saber até onde irá ter esse maravilhoso fruto do engenho humano [...] quando se entra a calcular as possibilidades do disco, como nos momentos de longo cismar causado por notícias no gênero das que li no "Discando" desta seção a respeito de novas invenções alemães (Correio da Manhã, 1 mar. 1931: 4).

E como leitor da coluna de Augusto Lopes Gonçalves - que parece ter sido, de fato, um importante difusor de uma imagem mais positiva do fonógrafo no meio erudito carioca -, Albuquerque da Costa passara, segundo suas próprias palavras, por uma evolução de espírito em favor do disco, o que o levou

a compreender perfeitamente a solução irresistível que a fonografia exerce sobre todos.

Verifiquei com os melhores elementos de julgamento o alcance infinitamente artístico da prodigiosa invenção.

Uma pessoa leiga tem no disco o veículo que vai conduzindo o seu espírito sempre mais e mais pelas regiões deslumbrantes que atingiu a música.

O simples estudioso encontra no fonógrafo o exemplo, palpitante de vida, que o faz receber lições inolvidáveis de interpretação ou de técnica (Correio da Manhã, 1 mar. 1931: 4 , grifo nosso).

Assim, o fonógrafo, além de ser útil para músicos, deveria começar a ser instalado em escolas e associações recreativas e educacionais de classe, visando 
sempre ao desenvolvimento do "amor pela boa música", a fim de transformar o brasileiro em um "povo que cada vez mais se apurará no seu paladar artístico" (Correio da Manhã, 1 mar. 1931: 4). Com esse alvo em mente, Costa ainda revelaria que iria propor à Academia Brasileira de Música

a realização de um curso anual sobre a evolução da música, constituído de conferências ilustradas com exemplos que na maioria dos casos serão fornecidos pelo disco.

Seguido este exemplo pelas outras sociedades existentes no país, feito com critério e de modo ameno, dentre em pouco tempo teremos a música apurada perfeitamente apreciada pelo povo, o qual assim irá aprendendo a distinguir o trigo do joio (Correio da Manhã, 1 mar. 1931: 4, grifos nossos).

Além das figuras ligadas ao Instituto, mais dois elementos alheios à escola de música - mas próximos dos pensamentos que lá circulavam atinentes ao emprego sério dos discos e das máquinas falantes - responderam às indagações do inquérito lançado pela seção "Música em discos”. O primeiro foi Aluísio Rocha, um "veterano fonófilo" que era um "distinto e culto conhecedor dos assuntos da fonografia" mais do que do mundo musical em si (Correio da Manhã, 8 fev. 1931: 7). Contudo, a sintonia entre Rocha e os professores não deixa de ser evidente. Ele iniciaria a exposição de seu ponto de vista comentando sobre o mesmo problema identificado por Lorenzo Fernandez:

Hoje como há cerca de trinta anos atrás, o disco exige o estrangulamento e o corte das músicas cuja execução exceda de quatro minutos, isto é, de todas as grandes obras musicais. A técnica fonográfica já resolveu o problema da gravação longa, porém, o interesse comercial dos grandes fabricantes de discos limitou-a ao cinema sonoro. Todas as tentativas nesse sentido no campo do disco artístico têm fracassado apesar do profundíssimo interesse que elas despertaram (Correio da Manhãa, 8 fev. 1931: 7, grifos nossos).

Se o "interesse comercial" impediria tamanho progresso do disco em termos de capacidade temporal de armazenamento de som, o investimento no disco artístico - ou seja, aquele que continha e transportava a "música imortal" ainda assim seria possível e desejável. Dessa maneira, se não haveria possibilidade ou disposição por parte das grandes gravadoras de produzir discos que propiciassem uma escuta integral das longas peças eruditas, às classes 
cultas, às sociedades culturais e à imprensa caberia "o trabalho de incutir nas massas o gosto pela boa música", estimulando a cultura musical. Não obstante, para o fonófilo especialista, não bastaria somente atentar-se para a audição:

O disco, por si só, não pode ser um elemento de cultura: precisa da assistência do livro, da História da Música, da biografia dos autores e da crítica criteriosa para produzir efeitos benéficos. Ninguém pode discriminar sem conhecer e a falta de critério na apreciação da música através do disco só pode produzir confusão e juízos errôneos, isto é, a sua influência na criação do gosto artístico será negativa (Correio da Manhã, 8 fev. 1931: 7, grifo nosso).

Dessa maneira, o especialista sugere que o "disco mau" - produzido fora das bases legítimas e reconhecidas dos conservatórios, mas que, sem dúvida, era então o mais consumido - poderia ser uma porta de entrada para o "disco bom":

como todo disco tem duas faces, sempre que fosse possível, seria conveniente que em uma delas se gravasse uma música boa, em vez de ocupá-las com duas músicas más. Isso é possível de fazer-se sem ser preciso sair do gênero da música mais vendável. Há músicas populares, por exemplo, de bom gosto e bem-feitas que, talvez, por isso mesmo, não encontram bom acolhimento entre os apreciadores do gênero, enquanto outras lamentáveis produções são procuradíssimas e fazem a fortuna dos seus autores e gravadores. Não seria o caso de gravá-las em um mesmo disco? Do mesmo modo se procederia nos repertórios mais elevados, excluindo o mais fino (Correio da Manhã, 8 fev. 1931: 7).

No entanto, esse seria apenas o primeiro passo a ser dado. O próximo deveria estar relacionado com a substituição desse plano difuso por uma "cultura sistematizada" em que a fonografia, o livro e a palavra escrita se completassem de modo a evitar que a "evolução do gosto artístico por meio do disco" fosse realizada de forma descontínua. Ademais, não se deveria esquecer do papel das chapas fonográficas no que concernia à memória sonora da nação:

a narração da história pátria e universal, o ensino do civismo e das regras do bom tom... tudo isso não seria mais do que o desenvolvimento da sua aplicação ao ensino das línguas vivas, ao registro de discursos e conferências, à gravação do folclore e ao estudo da fonologia, tal como já se faz na Europa e nos Estados Unidos (Correio da Manhã, 8 fev. 1931: 7, grifos nossos). 
O último entrevistado seria Itiberê da Cunha, um ex-prodígio do piano que, naquela época, era um compositor brasileiro conhecido no exterior, além de crítico musical e bacharel em direito. Para Cunha, o disco significava o mundo em "nossas mãos" em termos musicais. Daí o papel fundamental que esse artefato tecnológico assumia - pela capacidade de expandir o alcance dos sons - e a preocupação com o fato de não haver um projeto mais sistemático que visasse aplacar a ação perniciosa que essa mídia vinha empreendendo devido à "propaganda e difusão de coisas indesejáveis" (Correio da Manhã, 15 mar. 1931: 4). Nesse sentido, o jurista afirmaria que se não era possível fazer um "Tribunal da Música" - para condenar e absolver os sons fonográficos que circulavam sem critério -, que se investisse na melhor escola que poderia haver: uma boa discoteca. Isso visto que o bom disco - essa espécie de "livro sonoro" cujo alicerce se encontrava numa cultura escrita ordenadora da oralidade - seria o "único remédio capaz de sanear o ambiente" e "exercer medidas profiláticas que coloquem a música no nível saudável em que deve estar" (Correio da Manhã, 15 mar. 1931: 4).

\section{Por uma institucionalização da fonografia brasileira}

No final dos anos 1920, uma instituição pública italiana começava a chamar a atenção de agentes culturais brasileiros por se tratar, então, de um órgão de natureza peculiar no Brasil. Era a Discoteca do Estado, criada em 1928 pelo primeiro-ministro da Itália, o fascista Benito Mussolini. Como um verdadeiro "museu dos sons", esse novo empreendimento estatal ligado à fonografia se associava ao desejo de se "prolongar a personalidade além dos estreitos e angustiosos limites da vida humana", "um reclamo insistente do nosso sentimento" que teria se materializado ao longo dos séculos por meio do retrato, da estátua, da escrita, além de "outros recursos de fixação criado pelo homem". Dessa forma, entalhar a voz, os sons, em uma superfície redonda e plana era mais uma possibilidade advinda dos avanços técnico-científicos da modernidade (O Paiz, 16 dez. 1928: 3). 
Nessa mesma matéria jornalística, enfatizava-se que a finalidade do novo organismo italiano era conservar "em chapas fonográficas as vozes dos mais eminentes italianos dos nossos dias":

O próprio primeiro-ministro escolherá as pessoas de altos méritos cujas vozes a Itália deverá conservar amanhã, quando a morte os tiver para sempre emudecido.... Desse modo, Mussolini como Gabriel d'Annunzio, Marconi como Pio XI estarão, amanhã, vivos e audiveis nos salões da "Discoteca" embora a sombra da morte já tenha passado sobre seus corpos e emudecido, para sempre, as suas ilustres e sagradas gargantas... (O Paiz, 16 dez. 1928: 3, grifo nossos).

Tamanha perspectiva seria destacada no mesmo ano pelo escritor Mário de Andrade, que via nos trabalhos desse museu de discos recém-criado um fabuloso meio de "registrar todas as canções populares regionais e tradicionais italianas que, abandonadas na voz do povo, vão sendo esquecidas e substituídas por outras" (ANDRADE, 1928a: 2). Não era trivial que, pioneiramente, um intelectual da importância de Andrade estivesse atentando para as oportunidades que a nova fonografia passou a oferecer para o campo cultural. Antes mesmo da discussão empreendida pelos professores do Instituto Nacional de Música, portanto, o autor de Macunaíma afirmava acreditar que "certas vitrolas ortofônicas e certos discos Victor de gravação elétrica" conseguiam "uma verdade tal" que deveriam ser aproveitados para "a gente escutar arte assim da melhor" e em benefício da história, campo científico para o qual "a utilização das vitrolas modernas está se tornando uma precisão imperiosa" (ANDRADE, 1928b: 2). Assim, o modernista participava do movimento de reconhecimento da fonografia como uma técnica séria e respeitável, chancelando-a com argumentos que lembravam mesmo aqueles utilizados pelas empresas fonográficas na época, quando declarava, por exemplo, que "Hoje em dia já é possível a gente falar que gosta de fonógrafos e discos sem que os professores de música se riam. Não é mais possível que eles debiquem uma produção musical que pela perfeição [...] é manifestação perfeitamente legítima e agradável da arte" (ANDRADE, 1928b: 2, grifos nossos).

A concepção de que o Brasil também carecia de um órgão fonográfico oficial, patrocinado pelo Estado, era uma defesa que similarmente alcançara o 
Instituto Nacional de Música, quando os discos, como vimos, já haviam conquistado grande parte de seus professores. Um deles - ainda acanhado com sua opinião positiva acerca das máquinas falantes e, desse modo, identificado apenas pelo pseudônimo JRD - escreveria um artigo para $O$ Paiz explicando um pouco sobre a trajetória das discotecas públicas europeias e argumentando acerca da necessidade de o principal conservatório de música da capital brasileira (e possivelmente do país) assumir a tarefa de organizar um arquivo ou museu sonoro para o Brasil. De acordo com "JRD”, a mais antiga instituição fonográfica oficial foi fundada em 1899 na Academia de Ciências de Viena por Siegmund Exner, tornando-se logo um modelo para a formação das discotecas de Berlim e Budapeste, que tiveram como base as mesmas finalidades das quais se revestia o órgão pioneiro:

1) Registrar todas as línguas europeias do fim do século XIX, seguindo sua evolução assim como a dos dialetos; 2) Constituir uma coleção de documentos musicais, especialmente a respeito dos povos ainda primitivos; 3) Registrar os discursos e declamações de personagens eminentes (JRD, 1930: 7, grifos nossos).

No que tange ao papel do Instituto Nacional de Música, o professor em anonimato pontuaria que a instituição deveria organizar sua própria discoteca, o quanto antes possível, por três motivos: 1) devido à necessidade de se colecionarem "temas genuinamente de folclore brasileiro" - proposta lançada na Revista Weco, publicação periódica dirigida por Luciano Gallet; 2) em atenção aos estudos dos alunos dessa escola de música, que poderiam acompanhar, com o auxílio dos sons fonográficos, a evolução completa das obras primas, "dos tempos mais recuados até os nossos dias", proporcionandolhes também audições que os aproximassem da música viva executada com perfeição "pelas grandes orquestras, alemãs, francesas, italianas e americanas"; e 3) com a finalidade de "facilitar, pela conservação de discos antigos, a alunos de futuras gerações, a audição de grandes intérpretes já falecidos, sem precisar recorrer à tradição imprecisa e falha" (JRD, 1930: 7, grifos nossos). Nesse último ponto, o docente, logicamente, se referia à partitura, essa linguagem musical imperfeita que, apesar de sua importância institucional, não conseguiria 
alcançar toda a verdade do compositor: "Como seria agradável poderem os de hoje ouvir o próprio Chopin executando suas composições, se o fonógrafo tivesse sido seu contemporâneo" (JRD, 1930: 7, grifo nosso). Assim, a máquina falante seria, de fato, um meio legítimo para se escutar música - desde que os discos que a alimentassem fossem selecionados por elementos capazes: artistas ou um "amador de grande cultura e sensibilidades musicais", professores, conferencistas, enfim, "pessoas idôneas que saibam utilizar um tão eficaz e elevado meio de educação" (JRD, 1930: 7).

Outro encabulado comentador dos usos legítimos do disco seria o próprio Augusto Lopes Gonçalves, que, como já mencionado, passou a assinar sua coluna do Correio da Manhã somente a partir de 1933. Foi nesse período que o colunista começou a dedicar um grande espaço da coluna "Discando" para a questão da estruturação de discotecas. Mas ainda em uma edição de março de 1932, quando seus textos eram publicados sem assinatura, Gonçalves iniciaria sua argumentação afirmando que "as nações mais cultas estão desenvolvendo magnífica atividade no aproveitamento de todas as possibilidades da fonografia", ao que citava o exemplo dos governos da Alemanha, Hungria, Rússia, Áustria e França, que estariam, efetivamente, seguindo diretrizes da Liga das Nações, organismo internacional que havia sugerido que cada país organizasse sua discoteca nacional (Correio da Manhã, 27 mar. 1932: 4). Um pouco mais tarde, lamentando que o Brasil ainda carecesse de um empreendimento dessa natureza, Gonçalves defenderia veementemente que o governo brasileiro dotasse o país "de um arquivo fonográfico perfeito". Para o cronista, possuindo esse gênero de repositório, teria

\footnotetext{
a nossa nação tesouro magnífico, inapreciável, constituído das composições dos nossos músicos interpretadas por eles mesmos ou sob a sua direção, do registro da voz de todos os homens eminentes, da gravação das autênticas músicas populares na sua exata execução, dos variados modos de falar da nossa gente para que se proceda a estudos seguros de fonética e fonologia (Correio da Manhã, 5 jun. 1932: 5, grifos nossos).
} 
E a maior preocupação quanto ao retardo dessa criação estava ligada à perda, progressivamente maior, das "duas supremas expressões da alma brasileira: a língua e a música":

É para a realização de semelhante monumento que vimos chamando de contínuo a atenção dos poderes públicos, na certeza de que martelamos sobre um assunto da mais alta importância.

Naturalmente muito tempo há de passar até que se leve a efeito a criação da discoteca nacional e por isso quando as autoridades se decidirem a pôr em prática o que pregamos, execução que é fatal, já muita documentação insubstituível se terá perdido para honra e glória dos que tudo mandam e podem e quase sempre desmandam do que mandam (Correio da Manhã, 5 jun. 1932: 5, grifos nossos).

Finalmente, um terceiro texto publicado não seria de autoria do colunista do Correio da Manhã, mas de Luiz Heitor Corrêa - o mesmo que havia respondido ao inquérito "Os discos e os músicos" quase dois anos antes. Atuando então como bibliotecário do Instituto Nacional de Música, o jovem estudioso escreveria uma carta ao diretor dessa instituição que se tornaria pública por meio desse espaço cedido por Lopes Gonçalves. Nela, o músico informaria ao seu superior que o diretor do Instituto Internacional de Cooperação Intelectual - organismo associado à Liga das Nações e criado na cidade de Paris em 1926 com a finalidade de intermediar trocas científicas e intelectuais através de diversas subcomissões -, Henri Bonnet, solicitara a "atenção do governo brasileiro para as sugestões da Comissão de Peritos de Gravação Musical” (Correio da Manhã, 18 jun. 1933: 6). Acentuando o papel do Instituto Nacional de Música como um "centro de instrução e de propagação de cultura musical", Corrêa julgava que essas recomendações tinham de ser acompanhadas por essa escola de música, que deveria finalmente começar a seguir a "mentalidade moderna", "que considera os progressos mecânicos do seu século - cinema, fonógrafo, rádio, etc. - como incomparáveis auxiliares da pedagogia, da divulgação artística e científica" (Correio da Manhã, 18 jun. 1933: 6). O órgão da Liga das Nações, por meio de sua comissão especial para gravações sonoras, indicava que haveria um cenário ideal em que cada país deveria ter uma discoteca ou fonoteca nacional, "com recursos suficientes para 
existir e progredir, mantendo colaboração e intercâmbio com as demais instituições do mesmo gênero" (Correio da Manhã, 18 jun. 1933: 6). Segundo Luiz Heitor informaria ao seu diretor na carta,

As Universidades de Berlim e de Paris, aquela em que seu Instituto de Psicologia e esta com o Instituto Fonético, já deram a devida atenção ao grande problema que constitui uma obrigação insofismável do homem contemporâneo transmitir às gerações futuras, com os recursos do progresso que tem à sua disposição.

$1^{\circ}$ - a canção popular primitiva, até hoje conservada por tradição oral e prestes a desaparecer ante a ofensiva da civilização. É preciso observar que nem sempre as melodias primitivas podem ser notadas com os caracteres musicais modernos, em razão do seu ritmo livre e de entonações desusadas, com emprego de intervalos menores do que o semitom, etc. (é o caso de espécimes musicais orientais, ameríndios e outros). O grande papel do fonógrafo é, justamente, registrar a melodia d'aprés nature, sem as deformações que o compasso e a escala temperada, necessariamente, lhe infligem conservando, além do mais, com fidelidade, o que é imponderável - a interpretação - tão diversa de povo para povo!

$2^{\circ}$ - a interpretação autêntica das grandes obras musicais contemporâneas, executadas por seus autores ou sob sua direção.

$3^{\circ}$ - a maneira de executar e de interpretar dos nossos grandes virtuoses, a voz dos grandes homens, gritos de animais, como contribuição à História Natural, etc (Correio da Manhã, 18 jun. 1933: 6, grifos nossos).

Essas questões, em seu modo de ver, se revestiriam de grande urgência no caso do Brasil devido ao "fato de abrigarmos em nosso território populações no mais primitivo estágio de civilização". E não se trataria apenas de preservar a música indígena, mas também o "folclore nordestino, onde há reminiscências dos antigos modos de igreja, trazidos pelos jesuítas das primeiras catequeses, e cuja integridade e pureza são postas em risco, cada dia que passa pelo fastígio das danças de cidade, marchas de carnaval, sambas litorâneos e do próprio jazz ianque". Por isso, seria muito oportuno que o diretor, destinatário da carta, encontrasse uma forma de, em parceira com o ministro da Educação e Saúde Pública e com o reitor da universidade, preparar uma "sábia regulamentação" que permitisse ao "nosso Instituto" tornar a prescrição da Comissão efetiva, visto que ao Instituto Nacional de Música competiria “a organização da 
sugerida Fonoteca Nacional”. Para financiar empreendimento de tamanha envergadura, Luiz Heitor endossaria a sugestão do Instituto Internacional de Cooperação Intelectual, que propunha "a obrigatoriedade do depósito de um ou mais exemplares de discos gravados no Brasil" (Correio da Manhã, 18 jun. 1933: 6). Augusto Gonçalves concluiria a coluna daquela semana ratificando a carta e a posição de seu colega. E, coincidentemente ou não, pela primeira vez assinaria seu próprio espaço semanal de expressão de ideias - sem mais reservas quanto ao uso oficial e legítimo do disco.

Quase dois anos depois, em 1935, Mário de Andrade seria convidado pelo então prefeito de São Paulo, Fábio da Silva Prado, para dirigir o novo Departamento de Cultura. E uma de suas primeiras ações foi criar a Discoteca Pública Municipal, organismo que se tornaria um dos principais palcos de seu combate à "ciência livresca que não traz documentação nova e prática, brasileira" (ANDRADE, 1936). Como o primeiro órgão público fonográfico do Brasil, o empreendimento marioandradiano acabou absorvendo as práticas e discussões públicas que vinham delineando os limites de uma fonografia institucional brasileira nos últimos sete anos, período em que músicos (verdadeiros), intelectuais e entusiastas de um bom emprego dos discos e suas máquinas falantes (principalmente com o apoio do Estado) louvaram os avanços e produtos científicos e detraíram os "amadores" que produziam uma nova música fonográfica que surgia ignorando regras e balizas de uma cultura musical tradicional, baseada na velha tecnologia da escrita. E seria desse caldo que despontariam os principais trabalhos associados à Discoteca Pública de São Paulo: a "gravação científica do folclore nacional", que representava a verdade da cultura brasileira, então distante e perdida nos rincões do Norte do país (AZEVEDO, 1936: 10, grifo nosso); a captura sonora das vozes reais de homens ilustres do Brasil; e a divulgação e preservação das sonoridades produzidas por músicos verdadeiros, aqueles que tradicionalmente detinham, com toda a legitimidade, o monopólio da imortalidade sonora.

\section{Considerações finais}


Segundo Briggs e Burke (2016: 34), as mídias devem ser concebidas a partir de um contexto de sistema, compreendendo-se que "a velha e a nova mídia podem coexistir e realmente o faz, e que diferentes meios de comunicação podem competir entre si ou imitar um ao outro, bem como se complementar". Isso significa que não deveríamos nos surpreender de encontrar, nos anos 20 e 30, defesas que vinculavam o disco fonográfico ao livro - essa tecnologia tradicional de memória coletiva e comunicação (HOCHMAN, 2014: 13) -, principalmente quando o que estava em xeque era a posição de agentes culturais que detinham até então uma supremacia no que tange à divulgação e preservação das vozes e dos sons do Brasil: músicos formados em conservatórios, escritores e intelectuais; em comum, todos modelados pelas regras e delimitações da "gramática da escrita" ensinadas em ambientes institucionalizados.

Por essa perspectiva, olhar para trás levando-se em consideração um desenvolvimento ulterior da fonografia - a sua posterior naturalização ou banalização em diversos espaços sociais - significa deixar de atentar para nuances muito complexas, nas quais se inclui essa luta pela redelimitação de terreno exposta neste artigo. Por isso, devemos ter cautela quanto a uma vinculação imediata e exclusiva entre fonografia e música popular urbana quando, na realidade, estamos lidando com um mundo que - não podemos esquecer! - acabara de conhecer, de forma massiva, a possibilidade de reter um som exato, sem a intermediação da escrita. Ao mesmo tempo, parece-nos insuficiente compreender a discoteca pública criada por Mário de Andrade como fruto do gênio e vontade de um indivíduo (SAMPIETRI, 2009; CAROZZE, 2012) - ou mesmo atrelada ao movimento intelectual ao qual esse indivíduo pertenceu (MOYA, 2011) -, que simplesmente decidiu utilizar institucionalmente o disco - que sempre teria sido considerado um artefato digno de atenções prestigiosas. Nesse caso, as escolhas que circunscreveram esses projetos - hoje considerados autoritários (RUBIM, 2007) - de fonografia institucional estariam baseadas em preconceitos que, incompreensivelmente, vilipendiavam a música popular (urbana). Assim, selecionar o folclore, as 
"vozes de homens ilustres" e a música erudita ocidental para serem bases dos museus ou arquivos sonoros que foram fundados entre as décadas de 1930 e 1940 no Brasil parece um contrassenso, pois essas preferências não fazem mais sentido em seu conjunto ou estão simplesmente atreladas a um contexto político autoritário; mas como, por que e por quem ele foi construído? Dessa maneira, nosso objetivo neste artigo foi exatamente tentar compreender as escolhas dos homens que tinham a palavra quando o assunto eram os sons e as vozes que deveriam ser divulgados e preservados com a anuência e patrocínio do Estado naquele período.

Por isso trabalhamos com a concepção de "fonografia institucional" que se difere daquela mais comumente conhecida, a "comercial" - e, mais que isso, com parte de seu processo de construção no início dos anos 30. Por esse ângulo, temos um insólito protagonista, que tem vivido nas narrativas historiográficas como um objeto ora transparente (todos o conhecem e não precisamos fazer esforço algum para compreendê-lo) ora invisível (nem sequer aparecendo nas argumentações, cujo foco é apenas o conteúdo em si): o próprio disco. Nesse escrutínio, algumas indagações começaram a aparecer, tais como: o que era um disco fonográfico para esse grupo que se interessava em levá-lo para o âmago das políticas públicas de educação e cultura? De onde surgiram essas características? De sua forma, do modo como os "fonófilos" o viam, escutavam e utilizavam? Das propagandas que tentavam alinhá-lo a mídias e substâncias reconhecidas? Uma pergunta ingênua foi levando a outra, a outra e mais outra. E percebemos que o disco, para ser respeitado, tinha de ser como um livro; e sua base "natural" era a legitimada (e mais controlável) cultura escrita.

Entretanto, uma nova mídia que tinha o poder de retenção real do som não poderia estar totalmente vinculada ao livro, exatamente por ir além de suas funcionalidades - em especial quando se pensava nos avanços científicos que haviam permitido o aperfeiçoamento que alegadamente abriu as portas da fidelidade sonora. Por esse motivo, o perigo de se divulgar e preservar a oralidade instável e incontida de uma florescente urbanidade cosmopolita era 
diluído na possibilidade ímpar de se gravarem os sons associados à nação, não obstante ter-se um inédito e incômodo limite temporal no que concernia à captura de eventos sonoros.

Por esse prisma, podemos deslindar, talvez, outra interpretação para a habitual divisão tripartite que separava os tipos sonoro-musicais que preenchiam os discos e os caracterizavam como erudito, folclórico e popular legitimando o estudo e o investimento público nos dois primeiros e denunciando a ação perniciosa do último. Essa categorização, vista por vezes como fruto de preconceitos obscuros quanto à música popular (que, repetimos, angariaria maior simpatia institucional décadas depois, passando a ser, indiscutivelmente, alvo de maiores atenções acadêmicas), seria mais bem compreendida, a nosso ver, se fizéssemos duas separações: sonoridades préfonográficas e sonoridades substancialmente fonográficas. No primeiro caso, temos expressões sonoro-musicais que antecederam a técnica fonográfica e, consequentemente, não obedeciam a suas regras (com destaque para o limite temporal), sendo 1) ou baseadas na escrita musical ocidental que, tradicionalmente, garantia sua imperfeita, mas precisa, sobrevivência no espaço-tempo; 2) ou fundamentadas em uma oralidade pura, primitiva, simbólica no que tange a uma identidade nacional em construção por estarem afastadas dos grandes centros urbanos deturpadores de uma dita essência brasileira - que antes dificilmente poderia ser preservada por meio da escrita e, a partir do final dos anos 1920, passou a ser potencialmente alvo de gravações mais fidedignas em discos elétricos. No último caso, a referência se encontra em uma "música de conserva", nascida com a fonografia e em conformidade com todas as características que a máquina então impunha ou favorecia encontrando-se fora das reconhecidas formas de controle científico-intelectual.

Assim, o pensamento de agentes culturais que defendiam a fonografia com base, em grande medida, em uma "não-fonografia" passa a ser mais bem compreendido quando identificamos que tratava-se de uma defesa quase desesperada de um status quo, de uma posição social consolidada que vinha sendo solapada pelas possibilidades abertas por uma nova mídia. Além da 
Discoteca Pública de São Paulo, uma versão carioca desse tipo de instituição foi inaugurada em 1941, com todas as pompas, na então capital brasileira. Apesar de esquecido - provavelmente por não ter sido criado por um intelectual do porte de Mário de Andrade -, esse órgão cultural absorveu toda essa lógica que engendrou uma "não-fonografia" como eixo da fonografia institucional brasileira: seus alicerces foram, igualmente, a música erudita e gravações relativas aos sons reais do Brasil que deveriam se tornar um corpus documental a posteriori. Contudo, diferente de sua congênere paulista, a instituição fonográfica do velho Distrito Federal passou a preservar uma realidade nacional diferente, referente a um "Estado novo" e a um país urbano que então florescia. Mas essa é outra história.

\section{Referências}

ADORNO, Theodor. On the fetish-character in music. In: LEPPERT, Richard (Org.). Essays on music. Berkeley; Los Angeles: University of California Press, 2002.

ANDRADE, Mário de. O Fonógrafo. In: Arte, Diário Nacional, São Paulo, p. 2, 24 fev. 1928a.

ANDRADE, Mário de. Discos e fonógrafos. In: Arte, Diário Nacional, São Paulo, p. 2, 11 mar. 1928b.

ANDRADE, Mário. [Carta enviada para Câmara Cascudo]. Destinatário: Câmara Cascudo. São Paulo, 31 jul. 1936. In: MORAES, Marcos Antônio (Org.). Câmara Cascudo e Mário de Andrade: cartas, 1924-1944. São Paulo: Global, 2010.

AZEVEDO, Antonio Vicente de. Pela cultura. Revista do Arquivo Municipal, São Paulo, v. 28, p. 287-306, out. 1936.

BARBOSA, Orestes. Samba: sua história, seus poetas, seus músicos e seus cantores. Rio de Janeiro: Livraria Educadora, 1933.

BILAC, Olavo. Chronica. Kosmos, Rio de Janeiro, n. 9, p. 3, set. 1907.

BRIGGS, Asa; BURKE, Peter. Uma história social da mídia: de Gutenberg à Internet. 3 ed. Rio de Janeiro: Zahar, 2016. 
CAROZZE, Valquíria Maroti. A menina boba e a discoteca. 2012. $370 \mathrm{f}$. Dissertação (Mestrado em Filosofia) - Instituto de Estudos Brasileiros, Universidade de São Paulo, São Paulo, 2012.

CERTEAU, Michel de. A invenção do cotidiano: 1. artes de fazer. Petrópolis: Vozes, 2014.

CHARTIER, Roger. A história cultural: entre práticas e representações. Lisboa: Difel; Rio de Janeiro: Bertrand, 1988.

DIAS, Marcia Tosta. Os donos da voz: indústria fonográfica brasileira e a mundialização da cultura. São Paulo: Boitempo, 2000.

DOSSE, François. História do estruturalismo: o campo do signo, 1945-1966. São Paulo: UNESP, 2018a.

DOSSE, François. História do estruturalismo: o canto do cisne, de 1967 a nossos dias. São Paulo: UNESP, 2018 b.

FRANCESCHI, Humberto Moraes. A Casa Edison e seu tempo. Rio de Janeiro: Sarapuí, 2002.

GÓES, Custódio Fernandes. O nosso Hino Nacional deturpado em discos de gramofone. In: Correio musical, Correio da Manhã, Rio de Janeiro, p. 7, 7 nov. 1930.

GONZÁLEZ, Juliana Pérez. Da música folclórica à música mecânica: Mário de Andrade e o conceito de "música popular". São Paulo: Intermeios, 2015.

GOODY, Jack. The power of the written tradition. Washington; London: Smithsonian Institution, 2000.

GRAMOFOMANIA. A Noite, Rio de Janeiro, p. 7, 6 abril 1931.

HOCHMAN, Brian. Savage preservation: the ethnographic origins of modern media technology. Minneapolis: University of Minnesota, 2014.

JOTAENNE. Gatafunhos... Fon Fon, Rio de Janeiro, ano 10, n. 2, p. 36, 8 jan. 1916.

JRD. A educação pelo fonógrafo. O Paiz, Rio de Janeiro, p. 7, 13 abril 1930.

KATZ, Mark. Capturing sound: how technology has changed music. California; London: University of California Press, 2010.

KITTLER, Friedrich. A verdade do mundo técnico: ensaios sobre a genealogia da atualidade. Rio de Janeiro: Contraponto, 2017. 
LATOUR, Bruno. Reagregando o social: uma introdução à Teoria do AtorRede. Salvador: Edufba, 2012.

MORAES, José Geraldo Vinci de; MACHADO, Cacá. Escutando o Brasil. In: CARVALHO, Fábio Almeida de; EUGÊNIO, João Kennedy (Org.). Interpretações do Brasil. Rio de Janeiro: E-papers, 2014.

MORELLI, Rita de Cássia Lahoz. Indústria fonográfica: um estudo antropológico. Campinas: Unicamp, 2009.

MORTON JR, David L. Sound recording: the life history of technology. Baltimore: The John Hopkins University, 2006.

MOYA, Fernanda Nunes. A Discoteca Pública Municipal de São Paulo: um projeto modernista para a música nacional. São Paulo: Cultura Acadêmica, 2011.

NAPOLITANO, Marcos. A síncope das ideias: a questão da tradição na música popular brasileira. São Paulo: Fundação Perseu Abramo, 2007.

ONG, Walter. Oralidade e cultura escrita: a tecnologização da palavra. São Paulo: Papirus, 1998.

ORTIZ, Renato. A moderna tradição brasileira. São Paulo: Brasiliense, 1999.

PEREIRA, Avelino Romero. Música, sociedade e política: Alberto Nepomuceno e a República Musical. Rio de Janeiro: UFRJ, 2007.

RUBIM, Antonio Albino Canelas. Políticas culturais no Brasil: tristes tradições, enormes desafios. In: RUBIM, Antonio Albino Canelas (Org.). Políticas culturais no Brasil. Salvador: EDUFBA, 2007.

SAMPIETRI, C. E. A Discoteca Pública Municipal de São Paulo (19351945). 2009. 209 f. Dissertação (Mestrado em História) - Faculdade de Filosofia Letras e Ciências Humanas, Universidade de São Paulo, São Paulo, 2009.

STERNE, Jonathan. The audible past: cultural origins of sound reproduction. Durham: Duke University, 2003.

TINHORÃO, José Ramos. Música popular: do gramofone ao rádio e TV. 2 ed. São Paulo: Editora 34, 2014.

VELlOSO, Mônica Pimenta. As distintas retóricas do moderno. In: O moderno em revistas: representações do Rio de Janeiro de 1890 a 1930. Rio de Janeiro: Garamond, 2010. 
VICENTE, Eduardo. Da vitrola ao IPOD: uma história da indústria fonográfica no Brasil. São Paulo: Alameda, 2014.

WISNIK, José Miguel. O som e o sentido: uma outra história das músicas. São Paulo: Companhia das Letras, 1989.

Recebido em: 17 de julho de 2020 Aceito em: 30 de agosto de 2021 